\title{
Erratum to: Influences on the Aufbau
}

\author{
Christian Damböck
}

\section{Erratum to:}

C. Damböck (ed.), Influences on the Aufbau, Vienna Circle Institute Yearbook 18, https://doi.org/10.1007/978-3-319-21876-2

In the Book back matter, in "Reviews" in the section "Obituary" under "In Memory of Pat Suppes", the author name was missed in the print version (pg 298). Author name "Maria Carla Galavotti" has been included at the end of this Obituary.

The updated online version of this book can be found at https://doi.org/10.1007/978-3-319-21876-2 